\title{
Effect of Aging On Short Term Heart Rate Variability
}

\author{
Qazi Farzana Akhter' ${ }^{1}$, Qazi ShamimaAkhter ${ }^{2}$, Farhana Rohman $^{3}$, Susmita Sinha $^{4}$ Sybilla Ferdousi $^{5}$
}

\begin{abstract}
Background: Heart rate variability has been considered as an indicator of autonomic nerve function status. Few works have been done to assess the heart rate variability in normal healthy subjects in different countries. Objectives: To assess the cardiac autonomic nerve function status in healthy Bangladeshi population of different age groups by analyzing time domain measures of Heart Rate Variability. Methods: This cross sectional study was conducted in the Department of Physiology, Dhaka Medical College, Dhaka from the period of July 2012 to June 2013. For this purpose, a total number of 180 healthy subjects were selected with the age ranging from 15-60 years of both sexes. All the study subjects were divided into 3 different groups according to age (Control 15-30 years; middle age 31-45 years; older age 46-60 years). Each group included 60 subjects of which 30 were male and 30 were female. The subjects were selected from different areas of Dhaka city by personal contacts. HRV parameters were recorded by a 4 active channels, RMS Polyrite-D-2 machine For statistical analysis, one way ANOVA, unpaired Student's 't'-test and Pearson's correlation coefficient test were performed. as applicable. Results: Systolic blood pressure (SBP), diastolic blood pressure (DBP) were significantly $(\mathrm{p}<0.001)$ higher in older group in comparison to control \& middle age group. Again RR interval and RMSSD $(p<0.001)$, were significantly lower in older age group $(p<0.05)$ compared to control \& also to middle age group. But HR was found significantly higher $(p<0.05)$ in both middle and older subjects than control and also in older $(\mathrm{p}<0.05)$ compared to middle age. Correlation analysis showed moderate negative correlation of mean R-R with age in middle age whereas significant negative correlation for RMSSD both in middle and older age subjects.. Conclusion: In this study, markedly decreased cardiac parasympathetic function were found with aging process.
\end{abstract}

Key words: R-R, HR, RMSSD, older age, middle age

Bangladesh Soc Physiol. 2014, December; 9(2): 78-82 For Authors Affiliation, see end of text.

http://www.banglajol.info/index.php/JBSP

\section{Introduction}

ging is a gradual, continuous process
of spontaneous changes, begins at
birth and continues throughout the life. It involves maturation and development for children, adolescents and young adults. Then again many biological functions decline during middle and late age. Thus aging has both positive and negative aspects. ${ }^{1}$ Aging is inevitable and

Received January 2014; $\quad$ Accepted July 2014 as life expectancy increases day by day it become more important to understand the physiological mechanism associated with normal aging process. $^{2}$

Aging is a general physiological process that is yet poorly understood. Aging affects cells, tissues and organ systems. With aging normal cells stop divisions and eventually die under genetic control. ${ }^{3}$ With the advancement of age, there is a gradual decrease in body functions 
affecting mostly cardiovascular, respiratory, renal and nervous system including autonomic nerves. $^{4}$

Heart rate variability (HRV) refers to the beat to beat variation in the heart rate generated by the interplay of the sympathetic and parasympathetic nerve activity at the sinus node of the heart. ${ }^{5}$

Normal human aging is associated with changes in the autonomic control of several biological functions. The two components of ANS changes with age, but the degree of changes with aging is different because of their divergent neural pathway ${ }^{6}$. Aging alters the neurohormonal mechanism and causes a decline of SA nodal parasympathetic activity. That is why reduction of parasympathetic activity occurs with age. ${ }^{7}$

In advanced age due to impairment in the parasympathetic control of heart, there are increased risk of cardiovascular diseases, like arrhythmia and sudden cardiac death. So in elderly parasympathetic dysfunction shows altered sympathovagal activity and abnormal heart rate. ${ }^{8}$

Heart rate variability (HRV) reflects autonomic nerve function status. Normally HR variation is related to the balance between sympathetic \& parasympathetic nervous system which provides early better qualitative and quantitative interpretation of sympathovagal activity and can detect autonomic impairment. High HRV reflects good adaptability and well functioning autonomic control. On the other hand, reduced HRV acts as a strong predictor of many cardiac diseases. ${ }^{9}$

Time domain method determines the heart rate at any point in time or the intervals between successive normal QRS complex in a continuous ECG record. Common simple time domain variables include mean normal to normal QRS complex (NN) interval and the mean heart rate. Statistical time domain variables include the standard deviation of the NN interval (SDNN), root of the mean squared differences of successive NN intervals (RMSSD). ${ }^{5}$
Therefore, this study was carried out to assess the autonomic nerve function status in different age by analyzing HRV Time domain method to explore its role in occurrence of cardiovascular diseases.

\section{Methods}

This cross sectional study was carried out to observe the effect of age on autonomic nerve function by analyzing time domain measures of HRV in 180 healthy subjects with age ranging from 15-60 years, in the department of Physiology, Dhaka Medical College from July 2012 to June 2013. For this, total study subjects were divided into 3 groups according to their age such as control ( $15-30$ years) middle age( $31-45$ years) and older age (46-60 years) All the subjects were selected by personal contact from different areas of Dhaka city. All the subjects were apparently healthy and free from heart disease, hypertension, diabetes mellitus, chronic renal failure, any endocrine neurological disorders, Psychiatric illness and smoking .Protocol of this study was approved by the institutional ethical review committee.

After selection, the subjects were thoroughly informed about the objectives and detail procedure of the study. A written informed consent was taken in a prescribed form. To prepare for examination of cardiac autonomic function, the subjects were advised to have their meal by 9:00 pm in the night before the day of examination, to remain free from any physical or mental stress and not to take sedatives or any drugs affecting central nervous system. The subjects were also asked to take light breakfast and to avoid tea or coffee at the time of breakfast. On the day of examination the subject was advised to report the Autonomic Nerve Function Test Laboratory in the Department of Physiology of Bangabandhu Sheikh Mujib Medical University,Dhaka between 9:00 to 11:00 a.m on the day of examination.

Whenever the subject appeared in the department, he/she was interviewed and detail 
history regarding personal history, drug history, past medical history were taken. Then thorough physical examinations and anthropometric measurement including height, weight and BMI were taken. All information were recorded in a prefixed questionnaire. Then the subject was prepared to perform Autonomic Nerve Function Test. The subject was kept in complete bed rest in supine position for 15-20 minutes in a cool and calm laboratory environment. During this period subject was advised not to talk, eat or drink and also not to perform any physical or mental activity, even sleep. Then all preparations for recording of the Heart rate variability parameters were made by connecting the channels to a transducer for ECG and a 5 minutes short term recording was taken in a resting supine position and the HRV parameters were analysed by time domain method. All the data were expressed as mean \pm SE. For statistical analysis, one way ANOVA, unpaired Student's 't'-test and Pearson's correlation coefficient test were

Table I: Age and BMI in different groups ( $\mathrm{n}=180)$

\begin{tabular}{lccc}
\hline Parameters & $\begin{array}{c}\text { Control } \\
15-30 \text { years } \\
(\mathrm{n}=60)\end{array}$ & $\begin{array}{c}\text { Middle Age } \\
31-45 \text { years } \\
(\mathrm{n}=60)\end{array}$ & $\begin{array}{c}\text { Older Age } \\
46-60 \text { years } \\
(\mathrm{n}=60)\end{array}$ \\
\hline BMI & $20.55 \pm 1.21$ & $21.51 \pm 0.85^{ \pm}$ & $21.46 \pm 1.04^{\varnothing}$ \\
$\left(\mathrm{kg} / \mathrm{m}^{2}\right)$ & $(18.55-22.56)$ & $(19.03-23)$ & $(18.36-23.52)$ \\
Pulse & $73.22 \pm 5.64$ & $73.17 \pm 5.51$ & $75.20 \pm 6.61$ \\
$(\mathrm{beat} / \mathrm{min})$ & $(62-92)$ & $(60-88)$ & $(65-100)$ \\
SBP & $112.25 \pm 6.41$ & $113.75 \pm 6.61$ & $118.08 \pm 8.14$ \\
$(\mathrm{~mm} \mathrm{Hg})$ & $(100-120)$ & $(100-130)$ & $(100-130)$ \\
DBP & $73.58 \pm 5.30$ & $74.25 \pm 5.11$ & $77.42 \pm 6.61$ \\
$(\mathrm{~mm} \mathrm{Hg})$ & $(60-80)$ & $(70-85)$ & $(60-90)$ \\
\hline
\end{tabular}

Results are expressed as Mean \pm SE. Figures in parentheses indicate ranges. $\mathrm{BMI}=$ Body Mass Index $\mathrm{SBP}=$ Systolic blood pressure $\mathrm{DBP}=$ Diastolic blood pressure; $\pm(\mathrm{P}<0.05$; control vs middle age $) \quad \varnothing(\mathrm{P}$ $<0.05$; control vs older age $),(\mathrm{P}<0.05$; middle vs older age) performed by using SPSS (version-17) as applicable

\section{Results}

Resting pulse rate was almost similar in subjects of all age groups but BMI, SBP and DBP were significantly higher in older age groups ( Table I)

In this study, mean R-R interval were significantly lower in older subjects than control but not significantly different from middle age group. Again mean heart rate was significantly higher and RMSSD were significantly lower in middle \& older age groups. But SDNN was almost similar in subjects of all age groups. (Table II)

In this study correlation of HRV parameters with age showed that mean RR interval ,SDNN and RMSSD were negatively correlated and mean HR were positively correlated with age. RMSSD correlation was significant in middle and older age but RR interval was significant in middle age groups. (Table III)

Table II: Time domain measures of HRV in different groups $(\mathrm{n}=180)$

\begin{tabular}{lccc}
\hline Parameters & $\begin{array}{c}\text { Control } \\
15-30 \text { years }\end{array}$ & $\begin{array}{c}\text { Middle Age } \\
31-45 \text { years }\end{array}$ & $\begin{array}{c}\text { Older Age } \\
46-60 \text { years }\end{array}$ \\
\hline Mean R-R & $0.82 \pm 0.10$ & $0.80 \pm 0.10$ & $0.78 \pm 0.11^{\varnothing}$ \\
interval $(\mathrm{sec})(0.62-1.05)$ & $(0.51-1.11)$ & $(0.57-1.06)$ \\
Mean HR & $73.15 \pm 8.32$ & $76.82 \pm 7.14^{ \pm} 80.42 \pm 9.80^{\varnothing}$, \\
(beat/min) & $(57-98)$ & $(56-96)$ & $(65-88)$ \\
SDNN & $76.11 \pm 18.65$ & $74.15 \pm 18.41$ & $71.30 \pm 18.31$ \\
$(\mathrm{~ms})$ & $(15.05-99.40)$ & $(15.05-97.24)$ & $(15.05-95.30)$ \\
RMSSD & $91.16 \pm 21.10$ & $69.79 \pm 15.722^{ \pm} 57.41 \pm 14.54^{\varnothing}$, \\
$(\mathrm{ms})$ & $(49.28-125.20)$ & $(43.25-89.94)$ & $(35.07-89.60)$ \\
\hline
\end{tabular}

Results are expressed as Mean \pm SE. Figures in parentheses indicate ranges. $\mathrm{R}-\mathrm{R}=$ Interval between successive QRS complex (sec), Mean HR = mean heart rate; $\mathrm{SDNN}=$ Standard deviation of $\mathrm{NN}$ interval; RMSSD $=$ Square root of mean squared differences between adjacent $\mathrm{NN}$ intervals; $\mathrm{ms}=$ millisecond; \pm $(\mathrm{P}<0.05$; control vs middle age $) \quad \varnothing(\mathrm{P}<0.05$; control vs older age $)>(\mathrm{P}<0.05 ;$ middle vs older age $)$ 
Table III: Correlation of some time domain parameters with age in different age groups

\begin{tabular}{|c|c|c|c|c|c|c|}
\hline \multirow[t]{2}{*}{ Parameters } & \multicolumn{2}{|c|}{ Control } & \multicolumn{2}{|c|}{ Middle } & \multicolumn{2}{|c|}{ Older } \\
\hline & $\mathrm{r}$ & $\mathrm{P}$ & $\mathrm{r}$ & $\mathrm{P}$ & $\mathrm{r}$ & $\mathrm{P}$ \\
\hline Mean R-Rinterval (sec) & -0.146 & 0.267 & -0.319 & $0.01^{*}$ & 0.091 & 0.487 \\
\hline MeanHR (beat/min) & 0.092 & 0.48 & 0.23 & 0.07 & 0.087 & 0.50 \\
\hline $\mathrm{SDNN}(\mathrm{ms})$ & -0.154 & 0.23 & -0.023 & 0.86 & -0.152 & 0.24 \\
\hline $\operatorname{RMSSD}(\mathrm{ms})$ & -0.154 & 0.23 & -.300 & $0.01^{*}$ & -.314 & $0.012^{*}$ \\
\hline
\end{tabular}

Pearson's correlation coefficient test was done to explore relationship between the age and parameters. ${ }^{*} \mathrm{p}<0.05$

\section{Discussion}

In the present study, findings of time domain HRV parameters in healthy subject of different age group were almost similar to those reported by the various research reports on HRV measures in health. ${ }^{10-19}$ Different time domain components of HRV has been used as marker of overall cardiac autonomic activity. The task force guideline for HRV analysis have demonstrated the interpretation of these parameters to understand the status, behavior and the balance between sympathetic and parasympathetic function due to their continuous interaction. The total power represents the variability of R-R interval and is the result of the total cardiac autonomic nervous activities and hormonal activities on heart. Therefore its lower value indicates lower modulation of cardiac autonomic nervous activities on heart. ${ }^{5}$

In the present study, mean values of R-R interval were similar in young and middle age groups but significant difference was found between older and younger groups . In addition, though mean heart rate in all age groups were within physiological limit but it was consistently higher in, middle and old age groups. Similar observations were e also reported. ${ }^{10,11}$

Again, among the other time domain parameters, SDNN have been failed to show any age effect whereas RMSSD were found consistently and significantly decreased in middle age and older people and also showed significant correlation with age in older subjects specially. No published data are available to compare these findings. Progressive senile are suggested by literatures for this deterioration of autonomic nerve function activity in aged person though the exact mechanisms are not yet clear. Among the changes, structural \& functional changes of SA node, progressively decreased baroreceptor sensitivity (BRS), reduced compliance of large elastic arteries and also decreased vascular wall receptor sensitivity and age related acceleration of adrenergic activity are particularly implicated in the reduced cardiac autonomic regulation . 7,20-24 The result of this study reflects the limitation developed in the modulation of cardiac vagal activity with the progression of age even in absence of other biological contributor in healthy subjects.

\section{Conclusion}

From this study it may be concluded that cardiac autonomic nerve function impairment occurs with the advancement of age which is characterized by markedly decreased cardiac parasympathetic activities with aging.

\section{Acknowledgement}

Authors of this study are thankful to the Department of Physiology, Bangabandhu Sheik Mujib Medical University for the support of recording of data by the polyrite $\mathrm{D}$ in their Autonomic Nerve Function Lab.

\section{Authors affiliation}

1. *Qazi Farzana Akhter, Assistant Professor, Department of Physiology, Uttara Adhunik Medical College, Dhaka.Email: qfarzanaakhter@gmail.com.

2. Qazi Shamima Akhter, Professor and Head, Dept. of Physiology, Dhaka Medical College (DMC), Dhaka.

3. Farhana Rohman, Assistant Professor, Department of Physiology, Delta Medical College, Dhaka. Email:rahman_farhana82@yahoo.com

4. Susmita Sinha, Assistant Professor, Department of Physiology, Eastern Medical College, Comilla. Email:scobido_9999@yahoo.com.

5. Sybilla Ferdousi, Assistant Professor, Department of Physiology, University Dental College, Dhaka. Email:tapu9111@yahoo.com

*For correspondance 


\section{References}

1. Mark BH and Jones TV. Merck Manual of Health and Aging, $1^{\text {st }}$ ed, Merck publishing, USA; 2005.

2. Sieck GC. Physiology of aging. J Appl Physiol. 2003; 95(4): 1333-34.

3. Ganong WF. Review of Medical Physiology, $17^{\text {th }}$ ed, The McGraw-Hill Companies, USA; 1995.

4. Rashid KM, Uddin K \& Hyder S. Health of the aged. Pak J Physiol. 2005; 6(2): 40-42.

5. Task Force of the European Society of Cardiology and the North American Society of Pacing and Electrophysiology, Heart Rate Variability: Standards of Measurement, Physiological Interpretation and Clinical Use. Circulation. 1996; 93: 1043-65.

6. Shibao C, Grijalva CG, Raj SR, Biaggioni I \& Griffin MR. Orthostatic hypotension related hospitalizations in the United States. Am J Med. 2007; 120(11): 975-80.

7. Shankar V \& Keeraiah S. Age Related changes in the parasympathetic control of the Heart. Int $\mathrm{J}$ Sci Res Publications. 2012; 2(6): 1-6.

8. Ramaekers D, Ector H, Aubert AE, Rubens A \& Werf FV. Is the female autonomic nervous system cardioprotective?. Eur Heart J. 1998; 19: 133441 .

9. Evereng $\{1 \mathrm{H}$, Dursunoglu D, Cobankara V, Polat B, Seleci D, Kabukeu S, Kaftan A, Semiz E, \& Kilic M. Heart Rate Variability in Patients with Rheumatoid Arthritis. Rheumatol Int. 2004; 2: 198-202.

10. Moodithaya S \& Avadhany ST 2011, 'Gender Differences in Age Related Changes in Cardiac autonomic nervous function', J Age Res, vol. 2012, Article ID 679345, pp. 1-7

11. Kuo TB, Lin T, Young CC, Li CL, Chen CF \& Chou. Effect of aging on gender differences in neural control of Heart Rate. Am J of Physiol. 1999; 277( 6): 2233-39.

12. Choi JB, Hong S, Nelesen R, Bardwell WA, Natarajan L, Schubert C, \& Dimdale JE. Age and ethnicity differences in short term Heart Rate Variability. Psych som Med. 2006; 68: 421-68.

13. Bigger JT, Fleiss JL, Steinman RC, Rolnitzky LM, Schneider WJ \& Stein PK. RR variability in healthy, middle aged person compared with patients with chronic coronary heart disease or recent acute myocardial infarction. Circulation. 1995; 91(7): 1936-43.

14. Narkiewiez K, Phillips BG, Kato M, Hering D, Bieniaszewaki L \& Somers VK. Gender selective interaction between aging and cardiovascular sympathetic activity. Am Heart Assoc. 2005; 45: 522-25.

15. Gandhi DK, Sigh J \& Kiran TD. Gender \& autonomic nervous system. Ind J Fund Appl Life Sci. $2011 ; 1(4)$ : 172-79.

16. Jahan K, Begum N, Ferdousi S. Power Spectral Analysis of Heart Rate Variability in Female Rheumatoid Arthritis Patients J Bangladesh Soc Physiol 2012;7(1):8-12.

17. Nayem M, Begum N, Ferdousi S. Assessment Of Autonomic Nerve Function In Patients With Irritable Bowel Syndrome. J Bangladesh Soc Physiol 2012;7(1):53-59

18. Ahmed M, Begum N, Ferdousi S. Assesment of Autonomic Nerve Function In Hypothyroids By Time Domain Method of Heart Rate Variability. J Bangladesh Soc Physiol 2012;7(1):48-52

19. Kiran TD, Patil VV, Latti RG \& Sandip GH. Gender selective interaction between aging and cardiovascular sympathetic activity. Pravara Med Rev. 2010; 5(2): 10-16.

20. Jones PP, Christou DD, Jordan J \& Seals DR. Baroreflex buffering reduced with age in healthy men. Circulation. 2003; 107: 1770-1774.

21. Shi X, Gallagher KM, O'Connor W \& Foreman $\mathrm{BH}$. Arterial and cardiopulmonary baro-reflex in 60-69 VS 18-36 yr old human. J Appl physiol. 1996; 80: 1903-10.

22. Huikuri HV, Koistinen MJ, Yli-M£yry S 1995, 'Impaired low frequency oscillations of heart rate in patients with prior acute myocardial infarction and life threatening arrhythmias', Am J cardiol, vol.76, no.1, pp. 56-60.

23. Seals DR \& Esler MD. Human aging and the sympathoadrenal system. J Physiol. 2000; 528 (3) : 407-17.

24. Grubb BP. Syncope in older patient. Hellenic J Cardiol. 2003; 44: 235-42. 